\title{
Plazma Pasta Borlama Yöntemiyle Borlanmış AISI D2 Çeliğinin Aşınma ve Elektrokimyasal Korozyon Davranışlarının İncelenmesi
}

\author{
Yusuf Kayalı1, Yılmaz Yalçın², Şükrü Ülker ${ }^{3}$ \\ ${ }^{1}$ Afyon Kocatepe Üniversitesi, Teknoloji Fakültesi, Metalurji ve Malzeme Mühendisliği Bölümü, Afyonkarahisar. \\ https://orcid.org/0000-0002-2449-7125 \\ ${ }^{2}$ Afyon Kocatepe Üniversitesi, Teknoloji Fakültesi, Metalurji ve Malzeme Mühendisliği Bölümü, Afyonkarahisar. \\ https://orcid.org/0000-0001-7773-8896 \\ ${ }^{3}$ Afyon Kocatepe Üniversitesi, Teknoloji Fakültesi, Makine Mühendisliği Bölümü, Afyonkarahisar. \\ https://orcid.org/0000-0002-2561-3044
}

e-posta: ykayali@aku.edu.tr, https://orcid.org/0000-0002-2449-7125

Geliş Tarihi: 03.10.2018 ; Kabul Tarihi: 24.03.2019

Öz

Bu çalışmada, AISI D2 soğuk iş takım çeliği, 700 ve $750{ }^{\circ} \mathrm{C}$ işlem sıcaklıklarında 2 ve 4 saat süreyle \%70 $\mathrm{H}_{2}$-\%30 Ar gaz karışımında, 10 mbar basınç altında ve ağılıkça \%100 Boraks pasta kullanılarak plazma pasta borlama yöntemi ile borlanmıştır. Deneyler sonucunda, çelik yüzeylerinde oluşan borür

Anahtar kelimeler AISI D2 Çeliği; Boraks; Plazma Pasta Borlama; Mikrosertlik; Aşınma; Elektrokimyasal Korozyon tabakalarının morfolojisi optik mikroskobu ile incelenmiştir. Sertlik değerleri, mikro-sertlik cihazı ile ölçülmüş ve tabaka üzerinde oluşturulan fazlar XRD yöntemi ile belirlenmiştir. XRD analizinde $\mathrm{FeB}, \mathrm{Fe}_{2} \mathrm{~B}$ ve CrB fazlarının borür tabakasının üzerinde oluştuğu görülmüştür. Sonuç olarak, borlanmış çeliklerde elde edilen borür tabakasının kalınlığının artan borlama sıcaklık ve süresi ile artığı görülmüştür. AISI D2 çeliğinin orijinal sertlik değeri $452 \mathrm{HV}_{0,05}$ iken, borlama işlemi sonucunda, $1789 \mathrm{HV}$ o,05 gibi oldukça yüksek bir değere arttığı tespit edilmiştir. Borlama işlemi, AISI D2 çeliğinin aşınma direncini artırırken, artan borlama sıcaklığı ve süresiyle azalma meydana gelmiştir. AISI D2 çeliğinin yüzey sertliği borlama işlemi ile artmıştır. Elektrokimyasal deneyler sonucunda, borlanmış çeliklerdeki korozyon direnci, borlanmamış çeliğe göre korozyon direnci artmıştır. Fakat artan borlama sıcaklığı ve süresi ile birlikte korozyon direnci biraz düşmüştür.

\section{Investigation of Wear and Electrochemical Corrosion Behaviour of Borided AISI D2 Steel by Plasma Paste Boriding Method}

\begin{abstract}
In this study, AISI D2 cold work tool steel was boronized with plasma cake boriding method at 70 and $\mathrm{H} 2 \mathrm{O} 30 \%$ Ar gas mixture under pressure of $10 \mathrm{mbar}$ and $100 \%$ by weight of Borax paste for 2 and 4 hours at 700 and $750{ }^{\circ} \mathrm{C}$ processing temperatures. As a result of the experiments, the morphology of the boride layers formed on the steel surfaces was examined by optical microscopy. The hardness values were measured by the micro-hardness tester and the phases formed on the layer were determined by XRD method. In the XRD analysis, $\mathrm{FeB}, \mathrm{Fe}_{2} \mathrm{~B}$ and $\mathrm{CrB}$ phases were formed on the boride layer. As a result, the thickness of the boride layer obtained in boronized steels increased with increasing boron temperature and duration. While the original hardness value of AISI D2 steel was 452 $\mathrm{HV}_{0,05}$, it was determined to increase to a very high value as $1789 \mathrm{HV} 0,05$ as a result of boriding process. The boriding process increased the abrasion resistance of AISI D2 steel, while the decrease in boron temperature and time was reduced. As a result of the electrochemical tests, the corrosion resistance in the borided steels increased compared to the non-borided steel. But with increasing boriding temperature and duration, corrosion resistance has decreased slightly.
\end{abstract}

Keywords

AISI D2 Steel; Borax; Plasma Paste Borided; Micro hardness; Wear; Electrochemical Corrosion 


\section{Giriş}

Çelik malzemeler günümüzde çok geniş bir kullanım alanına sahiptirler. Çelik malzemeler özellikle korozyona ve aşınmaya maruz kalan malzemelerdir. AISI D2 soğuk iş takım çeliği de: kırılmaya hassas kalıplarda, vida tarakları ve makaralarında, makas ağzı, freze, basmakalıplarında ve birçok uygulamada oldukça yaygın kullanılmaktadır. Kullanım yerlerine göre aşınmaya ve korozyona maruz kalmaktadır (Çiçek et al. 2012, Karabatak ve Kara 2016).

Malzemelerin aşınması ve korozyonu günümüz endüstrisinde oldukça yüksek ekonomik kayıplara neden olan problemlerdendir. Malzeme üzerine uygulanan yüzey işlemleri ile aşınma ve korozyon olumsuz etkileri azaltılabilmektedir (Şen 1997). Yüzey kaplama işlemleri, bir metalin yüzeyini metal, ametal veya organik madde ile kaplayarak, malzemeyi hem görünüş hem de fiziksel ve kimyasal bakımdan daha dayanıkı hale getirmek amacıyla yapılmaktadır (Uysal 2006). Son yıllarda metalik malzemelerin termo-kimyasal yöntemlerle kaplanması büyük önem kazanmıştır. Bu yöntemlerden biri olana borlama işlemi, diğer difüzyon esaslı yüzey işlemlerine (nitrürleme, karbürleme vs.) kıyasla daha üstün özelliklere sahiptir (Kayali 2011). Borlama işlemi ile yüksek sertlik, elde edilen sertliğini yüksek sıcaklıklarda da $\left(550-600{ }^{\circ} \mathrm{C}\right)$ koruması ve çok düşük sürtünme katsayısına sahip olması gibi üstün özelliklerinden dolayı birçok araştırmacı tarafından bor ve bor bileşikleri üzerine birçok sayıda çalışma yapılmıştır (Kara et al. 2016). Termo-kimyasal bir difüzyon işlemi olan Borlama, borun yüksek sıcaklıkta çeliğe yayınmasıyla çelik yüzeyinde $\mathrm{FeB}$ ve/veya $\mathrm{Fe}_{2} \mathrm{~B}^{\prime}$ dan oluşan fazlar meydana gelmektedir (Özbek et al. 2004, Kayali 2011, Campos et al. 2013). Bu elde edilen borür tabakasının tek fazlı bir yapıda (genellikle daha az gevrek olan $\mathrm{Fe}_{2} \mathrm{~B}$ ) olması arzu edilir (Tabur et al. 2009, Ulu et al. 2013). Çünkü FeB'nin ısıl genleşme katsayısı $\left(23 \times 10^{-6} /{ }^{\circ} \mathrm{C}\right)$, $\mathrm{Fe}_{2} \mathrm{~B}^{\prime}$ nin ısıl genleşme katsayısından $\left(7,85 \times 10^{-6} /{ }^{\circ} \mathrm{C}\right)$ büyüktür (Uslu et al.2007, Kayali 2013). İki fazlı sistemde oluşan $\mathrm{Fe}_{2} \mathrm{~B}$ ve $\mathrm{FeB}$ fazları arasındaki ısıl genleşme farklılıkları nedeni ile kaplama yüzeyinde oluşan çatlamalar tabakanın pul pul dökülmesine sebep olmaktadır (Jain and Sundararajan 2002).
Genellikle borlama işlemi, $700-1000{ }^{\circ} \mathrm{C}$ sıcaklık aralığında, 1-10 saat süreyle farklı borlama ortamlarında yapılmaktadır (Genel 2006, Uslu et al. 2007). Borlama işlemi katı, sıvı, gaz ve pasta ortamlarının yanında son yıllarda plazma destekli sistemlerde de yapılabilmektedir (Tabur et al. 2009, Güneş et al. 2011). Borlama endüstriyel olarak, yapı çelikleri, dökme çelikler gibi çoğu demir esaslı ve demir dışı metallere uygulanabilmektedir (Tabur et al. 2009, Kayali 2013).

AISI D2 soğuk iş takım çeliği günümüzde mühendislik malzemeleri olarak yaygın bir şekilde tercih edilmektedir. Fakat AISI D2 çeliğini endüstride kullanmak için bir takım yüzey sertleştirme işlemlerine tabii tutulması gerekir. Kullanılan yüzey sertleştirme yöntemleri arasında ilk akla gelen nitrürleme ve borlama işlemleridir. Literatüre baktığımızda çelik ve demir dışı metaller kutu, sıvı borlama yöntemleriyle ilgili birçok çalışmalar yapılmıştır. Fakat, plazma pasta borlama yöntemi yeni bir yöntem olduğu için çok fazla çalışma literatürde yoktur. Bu çalışmanın amacı, ülkemizde üretilen \%100 Boraks pasta kullanarak AISI D2 soğuk iş takım çeliğinin kutu borlama sıcaklıklarından daha düşük sıcaklıklarda plazma ortamında borlanarak, aşınma ve korozyon davranışlarının belirlenmesidir.

\section{Materyal ve Metot}

\subsection{Malzeme ve Plazma Pasta Borlama}

Deneylerde soğuk iş takım çeliği olarak bilinen ve birçok uygulamada oldukça yaygın kullanılan AISI D2 çelikleri kullanılmıştır. AISI D2 çeliğinin kimyasal bileşimi Çizelge 1'de, optik mikroyapı resmi ise Şekil $1^{\prime}$ 'de görülmektedir.

Çizelge 1. Deneylerde kullanılan çeliğin kimyasal bilesimi.

\begin{tabular}{lcccccc}
\hline Çelik & C & Cr & Si & Mn & Mo & V \\
\hline AISI D2 & 1.48 & 11.9 & 0.96 & 0.45 & 0.98 & 0.76
\end{tabular}




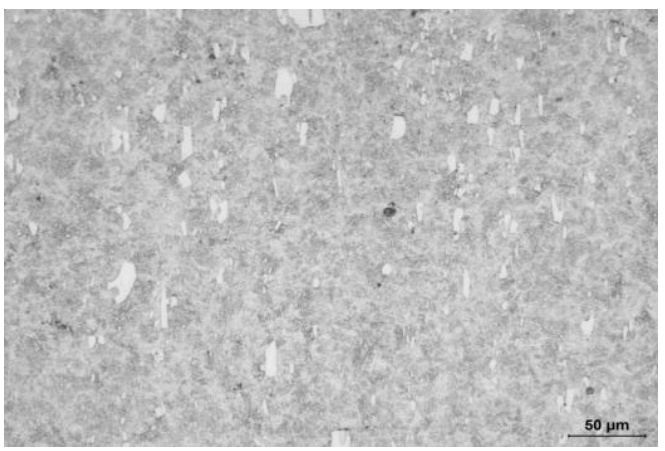

Şekil 1. AISI D2 çeliğinin optik mikroyapısı.

$17 \mathrm{~mm}$ çapında, $6 \mathrm{~mm}$ kalınlığında işlenen AISI D2 çeliğinden işlenen numuneler kaplama işleminden önce gerekli zımpara işlemlerinden geçirildikten sonra $1 \mu \mathrm{m} \mathrm{Al}_{2} \mathrm{O}_{3}$ solüsyonunda parlatılmışlardır. Metalografik olarak hazırlanan numuneler, \%100 boraksın suyu uçurulduktan sonra $100 \mu \mathrm{m}$ boyut altına öğütülüp alkol ile solüsyon haline getirilen ortama daldırılarak boraks tozu ile kaplanmıştır. Boraks kaplanan numune Şekil 2 de şematik olarak gösterilen plazma cihazının vakum haznesindeki katot üzerine yerleştirildikten sonra hazne basıncı vakum pompası ile $2 \times 10^{-2}$ mbar'a ayarlanmıştır. Ortama, 10 mbar basınç altında \%70 H2-\%30 Ar gaz karışımı verilerek, 700 ve $750{ }^{\circ} \mathrm{C}$ olmak üzere iki farklı sıcaklıkta, 2 ve 4 saat sürelerde plazma pasta borlama işlemi gerçekleştirilmiştir.

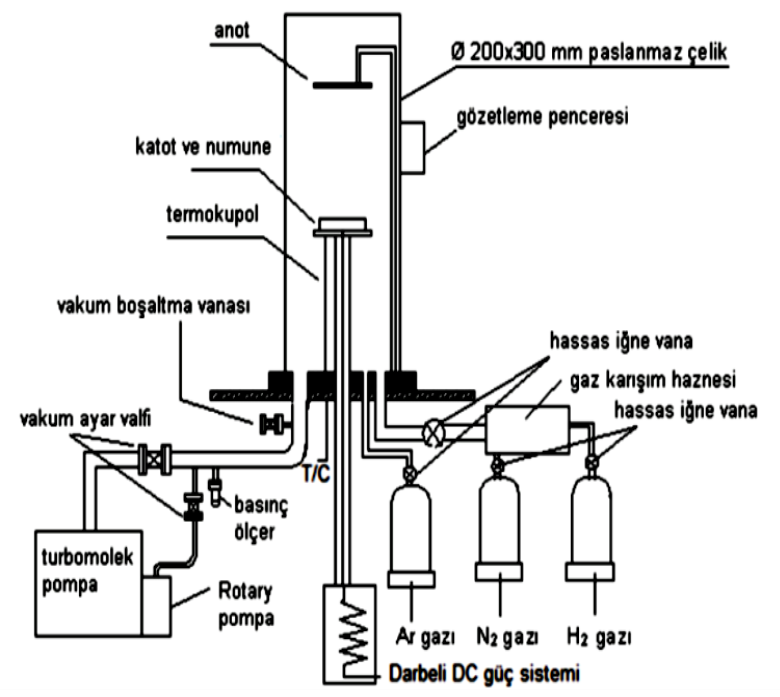

Şekil 2. Plazma Pasta Borlama Cihazının Şematik Gösterimi.

Plazma Pasta Borlama yöntemiyle borlanan AISI D2 çeliklerinden alınan numunelerin kesiti metalografik olarak hazırlandıktan sonra dağlanan numuneler
Olympus BX-60 model optik mikroskop ve Shimadzu XRD-6000 X-ışınları analizi yardımıyla karakterize edilmiştir. X-ışınları analizinde $\mathrm{CuK}_{\alpha}$ radyasyonu kullanılmıştır. Elde edilen bor tabakalarının kalınlığı optik mikroskoba bağlı bir aparat yardımıyla ölçülmüştür. Borlanmış AISI D2 çeliğinin sertlik değerleri Shimadzu HM-2 marka mikrosertlik cihazında 50 gr. yük altında yüzeyden matrise doğru sıra sertlik alınarak gerçekleştirilmiştir.

\subsection{Aşınma Testi}

\%100 Boraks Pasta ile Plazma pasta yöntemiyle borlanmış AISI D2 çeliğinin tribolojik özelliklerini incelemek için bilye-disk aşınma cihazı kullanılmıştır. $17 \mathrm{~mm}$ çapında borlanmış AISI D2 soğuk iş takım çelik disk numuneler, oda sıcaklığında $\left(25^{\circ} \mathrm{C}\right) 5 \mathrm{~N}$ yük altında ve sabit kayma hızında (yaklaşık 0,3 m/s) kuru ortamda, $500 \mathrm{~m}$ kayma mesafesinde, $8 \mathrm{~mm}$ çapındaki WC-Co bilyeye karşı aşındırılmıştır. Rugosimeter marka yüzey pürüzlülük cihazından aşınması deneyi yapılan numunelerinden, aşınma hacim miktarı belirlenerek, aşağıdan verilen Formül 1 'deki formülden aşınma hızı hesaplanmıştır.

Aşınma Hızı $=\frac{\text { Așınan Hacim Miktarı }}{(\text { Uygulanan Yük x Kayma Mesafesi) }},[\mathrm{mm} 3 /$

$\mathrm{Nm}]$

\subsection{Elektrokimyasal Korozyon Testi}

Elektrokimyasal korozyon numuneleri plazma pasta borlama yöntemiyle borlanan AISI D2 çeliğinin, elektrokimyasal korozyon deneyleri Gamry reference 600 potansiyostat/galvanostat ZRA ve Echem Analyst bilgisayar yazılımı ile gerçekleştirilmiştir. Elektrokimyasal korozyon deneylerine başlamadan önce $35{ }^{\circ} \mathrm{C}^{\prime} \mathrm{de} 15 \mathrm{dk}$ Aseton,15 dk Etanol ve $15 \mathrm{dk}$ çift distile edilmiş su ile ultrasonik banyoda temizlenen numuneler $40{ }^{\circ} \mathrm{C}$ 'de Etüv de kurutulmuştur. Elde edilen tafel eğrilerinden, polarizasyon direnci (Rp), korozyon akımı (Icor), korozyon hızı değerleri tespit edilmiştir. Korozyon akımının yüzey alanına bölünmesiyle korozyon akım yoğunluğu (i $i_{c o r r}$ ) bulunmuştur. \% İnhibisyon değeri aşağıdaki formülden hesaplanmıştır. Burada $i_{c}$ ve $i_{0}$ sırayla inhibitörlü ve inhibitörsüz korozyon hızlarını göstermektedir. 
$\%$ Inhibisyon $=\frac{i o-i c}{i o} \times 100$

\section{Bulgular ve Tartışma}

\subsection{Kaplama Özellikleri}

\%100 Boraks pasta ile farklı sıcaklık ve sürelerde plazma pasta borlama yöntemiyle borlanmış AISI D2 çeliğinin mikro yapı resimleri Şekil 3'de görülmektedir.
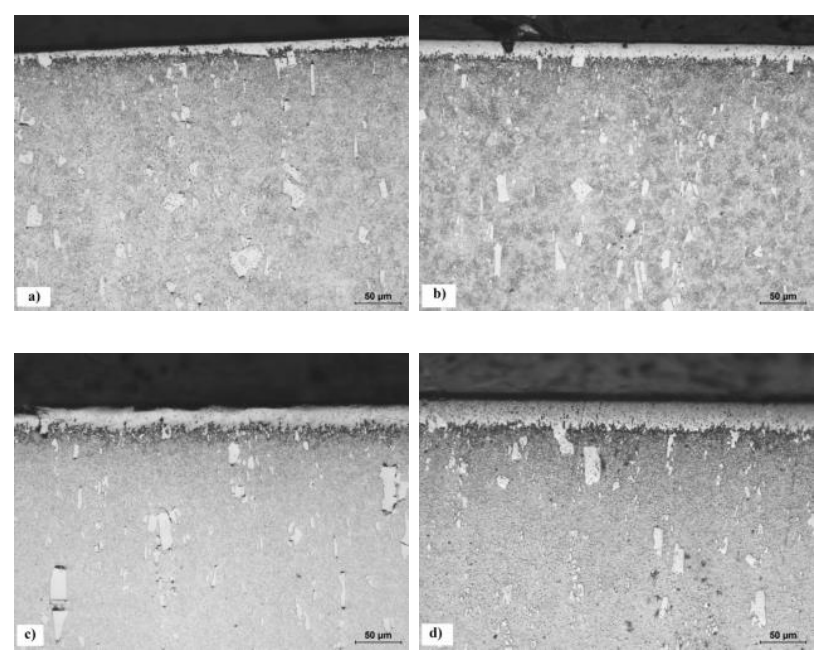

Şekil 3. $700{ }^{\circ} \mathrm{C}^{\prime} \mathrm{de}$ a) 2 saat, b) 4 saat, ve $750^{\circ} \mathrm{C}^{\prime} \mathrm{de}$, c) 2 saat d) 4 saat Plazma Pasta Borlama yöntemiyle borlanmış AISI D2 çeliğinin optik mikroyapı resimleri.

Plazma pasta borlanmış olan AISI D2 çeliğinin yüzeyinde oluşan borür tabakasının yüzey morfolojisinin pürüzsüz ve düz bir şekilde olduğu, matris ve ara yüzeyin birbirinden net bir şekilde ayrıldığı Şekil 3 deki optik mikroyapılarında görülmektedir.

\subsection{X-Işınları Difraksiyon Analizi}

XRD paternleri borür tabakasının $M B$ ve $M_{2} B$ ( $\mathrm{M}=$ Metal; $\mathrm{Fe}, \mathrm{Cr}$ ) türünde borürlerden oluştuğunu göstermektedir. AISI D2 çeliğin XRD analizlerinde borür tabakasında $\mathrm{FeB}, \mathrm{Fe}_{2} \mathrm{~B}$ ve $\mathrm{CrB}$ fazları tespit edilmiştir (Şekil 4) (Kayali 2013).
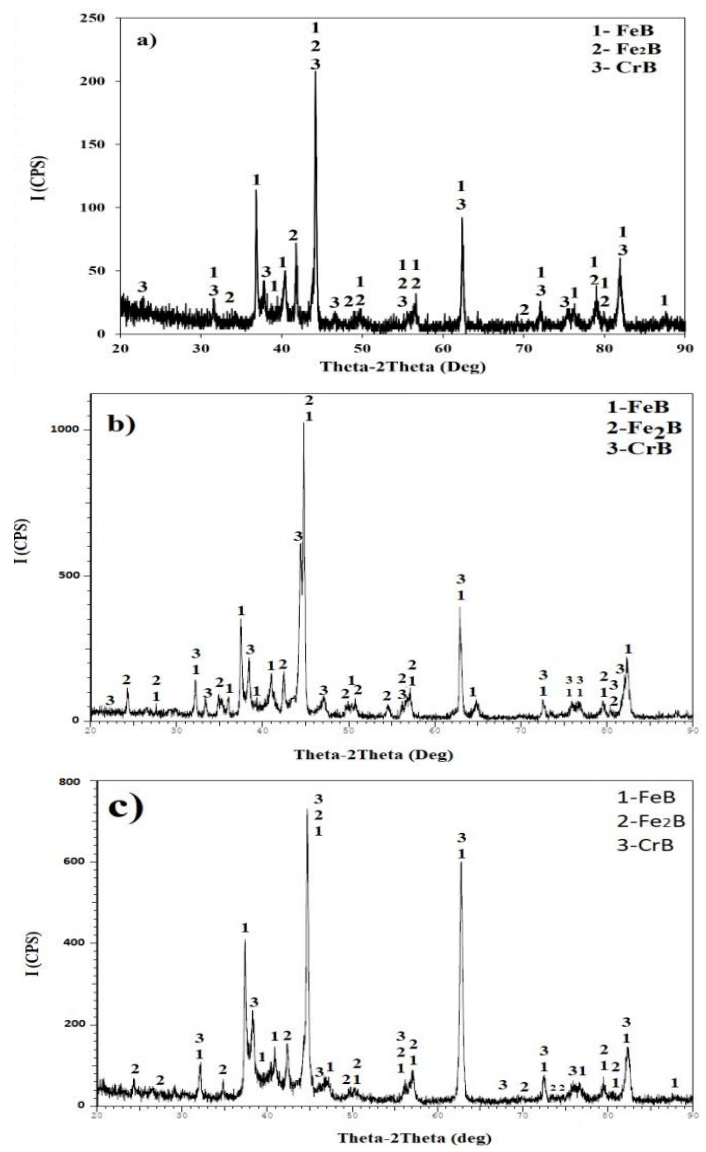

Şekil 4. a) $700{ }^{\circ} \mathrm{C}^{\prime}$ de 2 saat, b) $700{ }^{\circ} \mathrm{C}^{\prime}$ de 4 saat ve c) $750{ }^{\circ} \mathrm{C}$ 'de 2 saat Plazma Pasta borlanmış AISı D2 çeliğinin X-Işınları analizi.

\subsection{Tabaka Kalınlığı, Mikrosertlik}

Şekil 5 'te, borür tabakası kalınlığının, borlama süresi ve sıcaklığına bağlı olarak değişimi görülmektedir. Borlama işleminin sonucunda, borür tabakası kalınlığının, artan borlama süresi ve borlama sıcaklığı ile arttığı ve bu sonuçların literatürle uyumlu olduğu tespit edilmiştir (Çelikyürek et al. 2006).

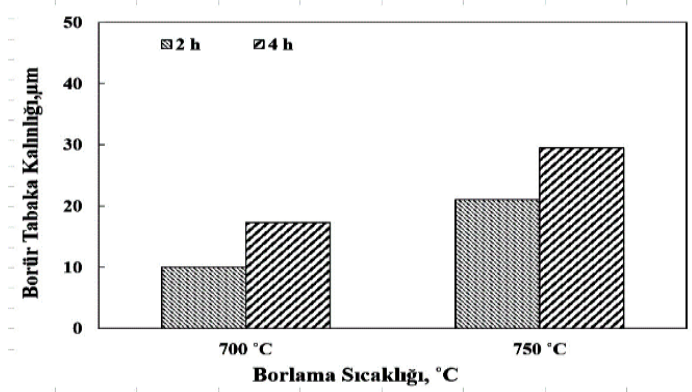

Şekil 5. Plazma pasta borlanmış AISI D2 çeliğinin sıcaklık ve süreye bağlı olarak borür tabaka kalınlıkları. 
AISI D2 çeliğinde elde edilen borür tabakası kalınlık değerleri 10,1-29,25 $\mu \mathrm{m}$ arasında değişmektedir. AISI D2 çeliği alaşımlı bir çelik olduğu için tabaka kalınlığı düşüktür. AISı D2 çeliğinin borür tabakasının kalınlığının diğer çeliklere göre daha az olmasının, içerisindeki alaşım elementlerinden kaynaklandığı düşünülmektedir (Kara et al. 2016).

AISI D2 çeliğinin yüzey sertlik değerleri plazma pasta borlama işlemi sonucunda borlama sıcaklığı ve süresine göre yaklaşık olarak 4-5 kat bir artış elde edilmiştir (Çelikyürek et al. 2006, İpek et al. 2012, Kayali 2013). Şekil 6'da, tüm kaplama işlem sıcaklık ve süreleri için yüzeyden içeriye doğru gidildikçe sertliğin düştüğü ve belli bir derinlikte değişmeden sabit kaldığı görülmektedir. Borlanmamış AISI D2 çeliğinin sertlik değerleri $452 \mathrm{HV}_{0.05}$ iken, plazma pasta borlama işlemi sonrası çeliklerin sertlik değerleri, zaman ve sıcaklığa bağlı olarak 1240 $\mathrm{HV}_{0.05}$ 'den $1798 \mathrm{HV}_{0.05}$ değişmektedir. Yüzeyde elde edilen yüksek sertliklerin içeri doğru ani düşüşler gösterdiği anlaşılmaktadır. Bu düşüş artan sıcaklık ve süre ile daha derinlerde gerçekleşmektedir. Bu, kaplama işleminin yayınma kontrollü olmasından dolayı beklenen bir davranış olarak değerlendirilmelidir.

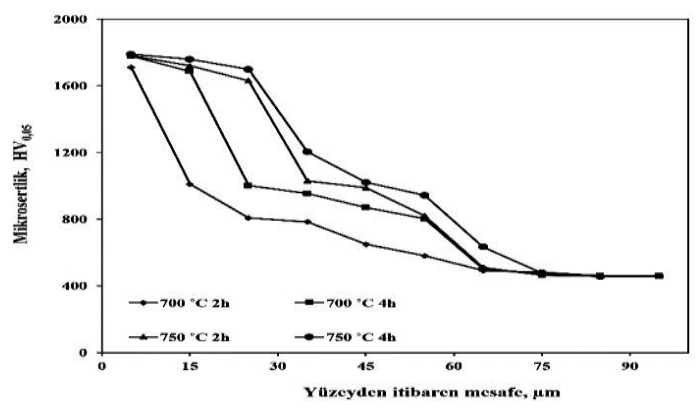

Şekil 6. \%100 Boraks pasta ile plazma pasta borlanmış AISI D2 çeliğinin yüzeyden içeriye doğru sertlik dağılımı.

\subsection{Aşınma Testi Analizi}

Aşınma deneyleri sonucunda borlama sıcaklığına ve süresine bağlı olarak aşınma hızı ve sürtünme grafikleri Şekil 7'de verilmiştir. İşlemsiz numuneler borlanmış numenelere oranla daha yüksek aşınma göstermiştir. Borlama sıcaklık ve süresinin artmasıyla aşınma hızında artış görülmüştür (Kayali et al. 2013).

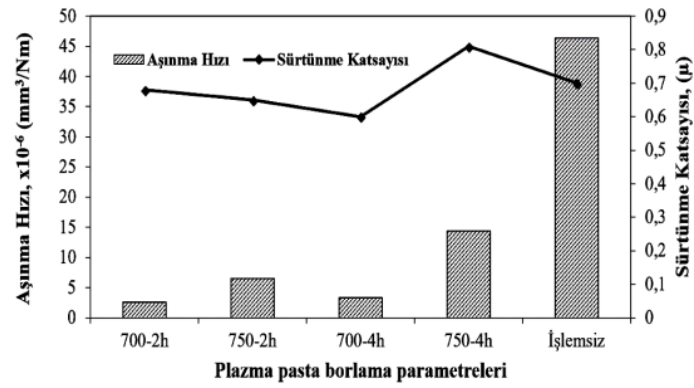

Şekil 7. Aşınma hızı ve Sürtünme katsayısı değerleri.

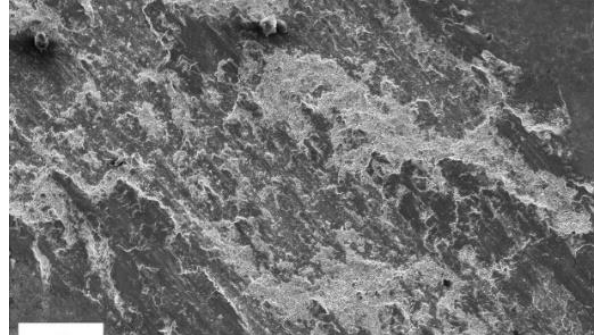

a)
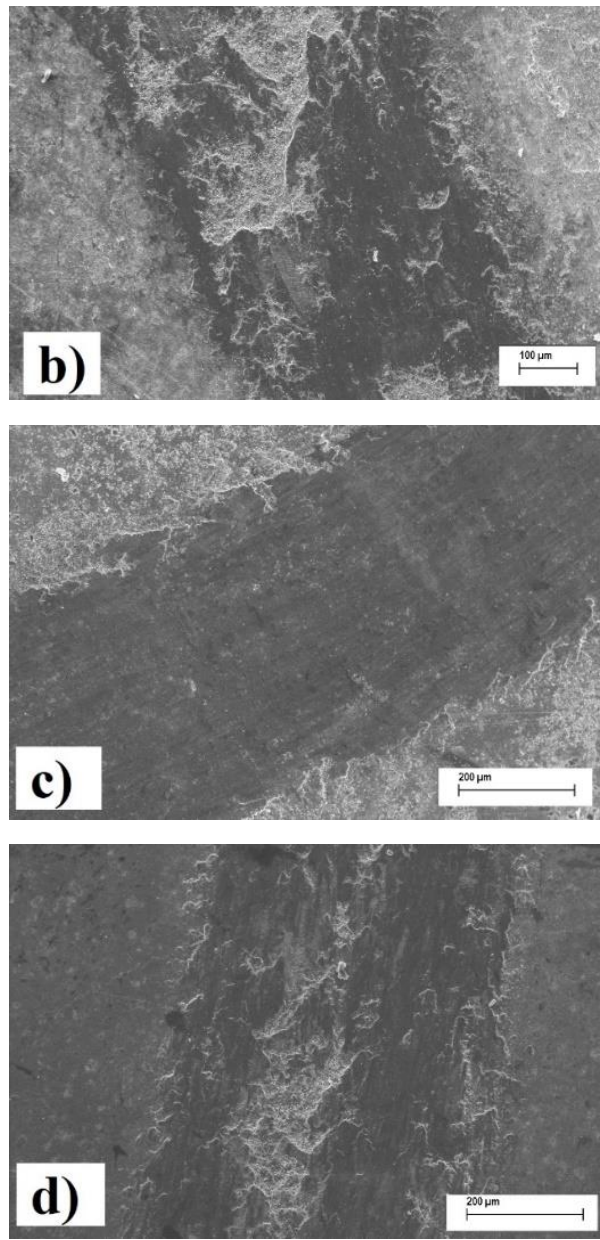

Şekil 8. a) İşlemsiz, $700{ }^{\circ} \mathrm{C}^{\prime}$ de b) 2 saat, c) 4 saat, $750{ }^{\circ} \mathrm{C}^{\prime}$ de d) 2 saat ve e) 4 saat borlanmış AISI D2 çeliğinin aşınma izi SEM resimleri. 


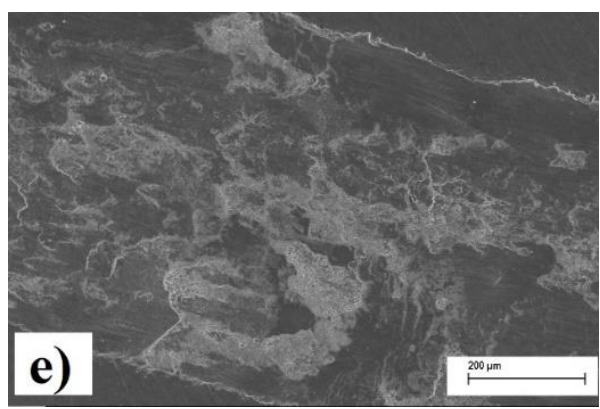

Şekil 8 (Devam) a) İşlemsiz, 700 قe'de b) 2 saat, c) 4 saat, 750 (a'C'de d) 2 saat ve e) 4 saat borlanmış AISI D2 çeliğinin aşınma izi SEM resimleri.

Şekil 8'de aşınmış numunelere ait SEM görüntüleri verilmiştir. Çok fazlı borür tabakasının oluşması tabakanın gevrekliğini artırmaktadır. FeB Fazı 1800$2000 \mathrm{HV}, \mathrm{Fe}_{2} \mathrm{~B}$ fazı 1400-1600 HV arasında sertlik değerlerine sahiptir. Altlık malzeme ve borür tabakası arasındaki geniş sertlik dağılımının olması, ortorombik yapıdaki $\mathrm{FeB}$ ile tetragonal yapıdaki $\mathrm{Fe}_{2} \mathrm{~B}$ 'un termal genleşme katsayılarının ve termal iletkenliklerinin farklı olmasından dolayı borür tabakası gevrekleşmektedir (Allaoui et al. 2006, Kulka et al. 2017). Tüm bunlara bağlı olarak kırılan tabaka abraziv aşınma sergileyerek aşınma direncinde düşüş gözlenmiştir.

\subsection{Elektrokimyasal Korozyon Testi Analizi}

Borlanmış ve borlanmamış AISI D2 çeliğin \%3,5 NaCl çözeltisinde 1 saat bekletme işleminden sonra Lineer ve Tafel polarizasyon yöntemi ile tespit edilen korozyon özellikleri ve Tafel eğrileri sırayla Çizelge 2 'de ve Şekil 9 de verilmiştir.

Çizelge 2 incelendiğinde borlanmış numunelerin $\% 3,5 \mathrm{NaCl}$ ortamında 1 saat bekletme sonrası polarizasyon (korozyon) akım yoğunluk ( $\mathrm{i}_{\text {corr }}$ ) değerleri azalmıştır. Polarizasyon akım yoğunluğu değerleri kaplanmamış durumda $0,983 \mu \mathrm{A} / \mathrm{cm}^{2}$ iken, borlanmış numunelerde borlama süresi ve sıcaklı̆̆ına bağlı olarak polarizasyon akım yoğunluğu değeri $\quad 0,245-0,474 \quad \mu \mathrm{A} / \mathrm{cm}^{2} \quad$ aralığında değişmektedir. Borlanmış AISI D2 çeliğin korozyon direnci oluşan borür tabakasıyla artmıştır (Sinha, 1991, Kariofillis et al. 2006). Plazma Pasta borlama yöntemiyle borlanmış numunelerin tabaka kalınlığı artıkça icorr. Değeri artarken, Rp değeri ve \% inhibisyon değeri azalmaktadır. Ayrıca $\mathrm{Rp}$ (polarizasyon direnci) ve korozyon hızı değerlerinin (mpy), i $i_{\text {corr }}$ değerleri ile uyumlu olduğu gözlenmektedir (Şekil 9).

Bor kaplanmış çeliklerin korozyon dirençleri genellikle kaplamaların karakteristik özelliklerinden olan mikroçatlakların ve porozitelerin miktarına bağlıdır. Bu poroziteler kaplamaların sıkılığını negatif yönde etkiler ve kaplamaların önemli derecede korozyon direncini azaltır. Bu oluşan boşlukların miktarı kaplamadaki mikroyapı ile ilişkilidir (Campos et al. 2006, Liu et al. 2006).

Çizelge 2. Plazma Pasta Borlanmış D2 çeliğinin \%3,5 NaCl Çözeltisinde Korozyon Değerleri.

\begin{tabular}{|c|c|c|c|c|}
\hline \multirow[b]{2}{*}{ Yapılan İşlemler } & \multicolumn{3}{|c|}{ Tafel Polarizasyon Sonuçları } & \multirow{2}{*}{$\begin{array}{c}\% \\
\text { İnhibis } \\
\text { yon }\end{array}$} \\
\hline & $\begin{array}{l}\text { Ecorr. } \\
(\mathrm{mV})\end{array}$ & $\begin{array}{c}\text { icorr. } \\
\left(\mu \mathrm{A} / \mathrm{cm}^{2}\right)\end{array}$ & $\begin{array}{l}\text { Kor. } \\
\text { Hizı } \\
\text { (mpy) }\end{array}$ & \\
\hline İşlemsiz D2 & -62.4 & 0.983 & 0.255 & - \\
\hline $700{ }^{\circ} \mathrm{C} 2 \mathrm{~h}$ PPB D2 & -23.7 & 0.245 & 0.064 & 75.07 \\
\hline $700^{\circ} \mathrm{C} 4 \mathrm{~h}$ PPB D2 & 8.1 & 0.354 & 0.092 & 63.98 \\
\hline $750^{\circ} \mathrm{C} 2 \mathrm{~h}$ PPB D2 & 8.4 & 0.418 & 0.108 & 57.47 \\
\hline \multirow[t]{2}{*}{$750^{\circ} \mathrm{C} 4 \mathrm{~h}$ PPB D2 } & 5.6 & 0.474 & 0.123 & 51.78 \\
\hline & \multicolumn{4}{|c|}{ Lineer Polarizasyon Sonuçları } \\
\hline Yapılan İşlemler & $\begin{array}{l}\mathrm{Rp} \\
(\mathrm{k} \Omega)\end{array}$ & $\begin{array}{l}\text { Ecorr } \\
\text { (mV) }\end{array}$ & $\begin{array}{l}\text { Icorr } \\
(\mu \mathrm{A})\end{array}$ & Corre. \\
\hline İşlemsiz D2 & 30.907 & -60.6 & 0.844 & 0.994 \\
\hline $700^{\circ} \mathrm{C} 2 \mathrm{~h}$ PPB D2 & 86.932 & -21.4 & 0.300 & 0.989 \\
\hline $700^{\circ} \mathrm{C} 4 \mathrm{~h}$ PPB D2 & 80.465 & 7.9 & 0.324 & 0.995 \\
\hline $750^{\circ} \mathrm{C} 2 \mathrm{~h}$ PPB D2 & 65.893 & 8.7 & 0.395 & 0.999 \\
\hline $750^{\circ} \mathrm{C} 4 \mathrm{~h}$ PPB D2 & 63.935 & 7.1 & 0.408 & 0.996 \\
\hline
\end{tabular}

Oluşan oksit filmi kırılınca saldırgan $\mathrm{Cl}^{-}$iyonları çelik yüzeyine daha kolay ulaşmaktadır. Küçük anot, büyük katot etkisiyle malzeme hızlı bir şekilde korozyona uğramaktadır. Hem sıcaklığı hem de kaplama süresinin arttırılması ile daha kalın bir borür tabakası oluşmaktadır. Bu ise borür tabakasının çeliğin yüzeyinden daha kolay ayrılmasına ve hatta borür kaplama tabakasında çatlak oluşumuna neden olmaktadır (Campos et al. 2006). 


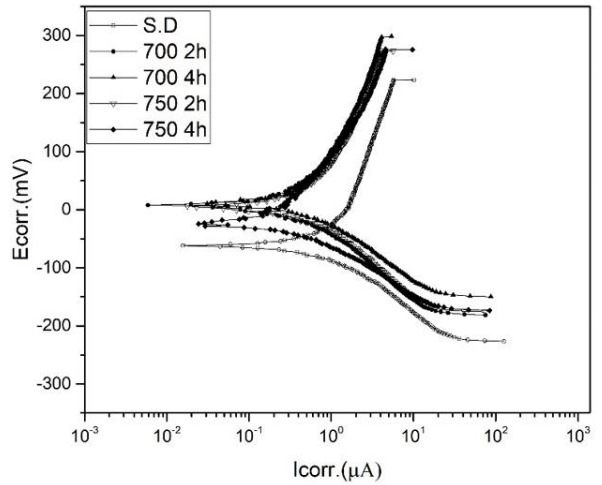

Şekil 9. \% 3,5 NaCl Çözeltisinde 1 saat bekletilmiş numunelerin Tafel Eğrileri.

Korozyon sonrası yapılan SEM-Edx analizleri Şekil 10 da görülmektedir. Şekil 6a da İşlemsiz AISI D2 çeliğinin yüzeyinde çözeltiden gelen saldırgan $\mathrm{Cl}$ iyonlarının, $700{ }^{\circ} \mathrm{C} 2$ saat borlanmış olan numuneye göre daha çok birikmesi ve bu klorür iyonları çok agresif olduğu ve demirle çözünür tuz kompleksleri oluşturduğu için korozyon hızını artırdığı söylenebilir. $700{ }^{\circ} \mathrm{C}$ de 2 saat borlanmış numunenin yüzeyinde saldırgan $\mathrm{Cl}$ iyonları yok denecek kadar çok az miktarda EDX analizlerinde görülmektedir (Şekil 10b). Bu yüzden korozyon direnci en iyidir. Ayrıca, yüzeyde bulunan oksijen ve demir birbirleri ile birleşerek oksit ve hidroksitleri oluşturmuş olabilir.
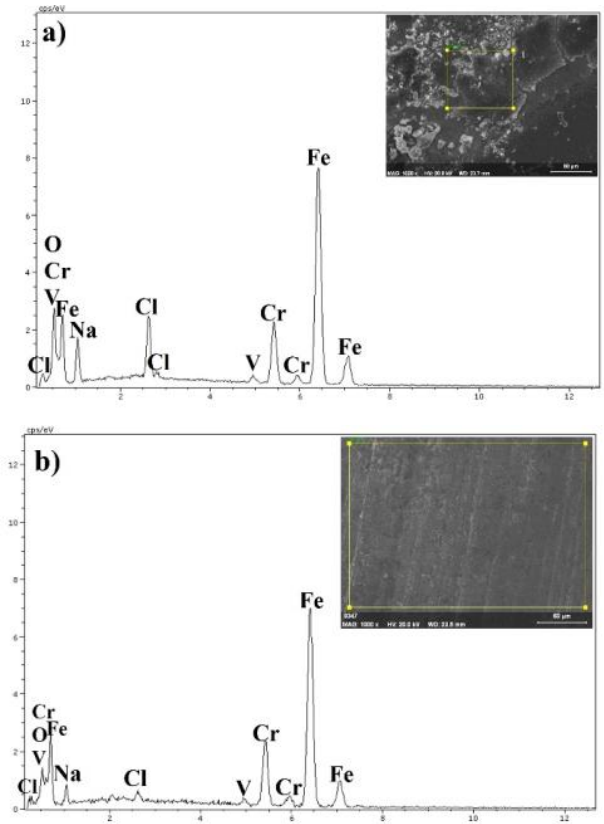

Şekil 10. a) İşlemsiz, b) $700{ }^{\circ} \mathrm{C} 2$ saat plazma Pasta borlanmış AISI D2 çeliğinin $\% 3,5 \mathrm{NaCl}$ çözeltisinde korozyon deneyleri sonrası EDx Analizi.

\section{Sonuçlar}

Bu çalışmadan aşağıdaki sonuçlar çıkarılabilir:

$\checkmark$ Plazma pasta borlama ile $\% 100$ boraks kullanılarak, AISI D2 çeliğinin yüzeyinde, FeB, $\mathrm{Fe}_{2} \mathrm{~B}$ ve $\mathrm{CrB}$ fazlarından oluşan düz ve pürüzsüz morfolojide bir bor tabakası elde edilmiştir.

Plazma ortamının kimyasal reaksiyonu daha fazla etkinleştirmesinden dolayı kutu borlama yöntemleriyle elde edilen borür tabakaları daha düşük sıcaklıklarda elde edilmiştir.

Yüzeyde oluşan borür tabakasının kalınlığı artan borlama sıcaklığı ve süresine bağlı olarak artmıştır.

Borlama işlemi ile AISI D2 soğuk iş takım çeliğinin yüzey sertliği yaklaşık olarak 4-5 kat artmıştır.

İşlemsiz numuneler borlanmış numunelere oranla daha yüksek aşınma göstermiştir. Borlama sıcaklık ve süresinin artmasıyla aşınma hızında artış görülmüştür.

Borlama işlemi ile birlikte AISI D2 çeliğinin korozyon direnci artmıştır. Korozyon direnci, kaplanmış nunumeler arsında kaplama kalınlığı düşük olan numunelerde daha iyidir. Kaplama kalınlığı arttıkça, korozyon direnci azalmıştır.

\section{Teşekkür}

$\mathrm{Bu}$ çalışma için Bu çalışma için 17.Kariyer.232 ve 18.Kariyer.244 nolu projeleri destekleyen Afyon Kocatepe Üniversitesi, Bilimsel Araştırma Projeleri Komisyonuna teşekkür ederiz.

\section{Kaynaklar}

Allaoui, O., Bouaouadja, N., Saindernan, G., 2006. Characterization of boronized layers on a XC38 
steel. Surface \& Coatings Technology, 201, 3475-3482.

Campos, I., Palomar, M., Amador, A., Ganem, R., Martinez, J., 2006. Evaluation of the corrosion resistance of iron boride coatings obtained by paste boriding process. Surface \& Coatings Technology, 201, 2438-2442.

Campos, I., Ramírez, G., Figueroa, F., Villa Velázquez, C., 2013. Paste Boriding Process: Evaluation of Boron Mobility on Borided Steels. Surface Engineering, 23(3), 216-222.

Celikyurek, I., Baksan, B., Torun, O., Gurler, R., 2006. Boronizing of iron aluminide Fe72Al28. Intermetallics, 14, 136-141.

Çiçek, A., Ekici, E., Uygur, i., Akıncıoğlu, S., Kıvak, T., 2012. AISI D2 soğuk iş takım çeliğinin delinmesinde derin kriyojenik işlemin takım ömrü üzerindeki etkilerinin araştırılması. SDU International Journal of Technologic Sciences, 4(1), 1-9.

Genel, K., 2006. Boriding kinetics of $\mathrm{H} 13$ steel. Vacuum, 80, 451-457.

Güneş, ì., Ülker, Ş., Taktak, Ş., 2011. Plasma Paste Boronizing of AISI 8620, 52100 AND 440C Steels. Materials and Design, 32(4), 2380-2386.

Ipek, M., Efe, G.C., Ozbek, I., Zeytin, S., Bindal, C., 2012. Investigation of Boronizing Kinetics of AISI 51100 Steel. Journal of Materials Engineering And Performance, 21(5), 733-738.

Jain, V., Sundararajan, G., 2002. Influence of the Pack Thickness of the Boronizing Mixture on the Boriding of Steel. Surface and Coatings Technology, 149, 21-26.

Kara, R., Çolak, F., Kayalı, Y., 2016. Investigation of Wear and Adhesion Behaviors of Borided Steels. Transactions of the Indian Institute of Metals, 69(6), 1169-1177.

Karabatak, M., Kara, F., 2016. AISI D2 Soğuk İş Takım Çeliğinin Sert Tornalanmasında Yüzey
Pürüzlülüğünün Deneysel Optimizasyonu. Politeknik Dergisi, 19 (3), 349-355.

Kariofillis, G.K., Kiourtsidis, G.E., Tsipas, D.N., 2006. Corrosion behavior of borided AISI H13 hot work steel. Surface \& Coatings Technology, 201, 19-24.

Kayalı, Y., 2011. Borlanmış AISI 316 L paslanmaz çeliğin korozyon ve Aşınma davranışların incelenmesi. Doktora tezi A.K.Ü., Fen Bil. Ens., Afyon.

Kayalı, Y., 2013. Investigation of the Diffusion Kinetics of Borided Stainless Steels. The Physics of Metals and Metallography, 114 (12), 10611068.

Kayalı, Y., 2015. Investigation of Diffusion Kinetics of Borided AISI P20 Steel in Micro-Wave Furnace. Vacuum, 121, 129-134.

Kayalı, Y., Büyüksağış, A., Yalıın, Y., 2013. Investigation of Corrosion and Wear Behaviors of Boronized AISI 316L Stainless Steel. Journal of Metals And Materials International, 19 (5), 1053-1061.

Kulka, M., Makuch, N. Piasecki, A. 2017. Nanomechanical characterization and fracture toughness of $\mathrm{FeB}$ and $\mathrm{Fe}_{2} \mathrm{~B}$ iron borides produced by gas boriding of Armco iron. Surface \& Coatings Technology, 325, 515-532.

Liu, C., Lin, G., Yang, D., Qi, M., 2006. In vitro corrosion behavior of multilayered $\mathrm{Ti} / \mathrm{TiN}$ coating on biomedical AISI $316 \mathrm{~L}$ stainless steel. Surface \& Coatings Technology, 200, 40114016.

Özbek, İ., Sen, Ş., Ipek, M., Bindal, C., Zeytin, S., Ucisik, A.H., 2004. A mechanical aspect of borides formed on the AISI $440 \mathrm{C}$ stainless-steel. Vacuum 73, 643-648.

Sinha, A. K., 1991. Boriding(Boronising) of Steels. In: ASM Handbook, V. 4, J. Heat Treating, Materials Park: ASM International, 437-447. 
Şen, U., 1997. Küresel Grafitli Dökme Demirlerin Bor Kaplanması ve Kaplama Özellikleri. Doktora tezi i.T.ü., Fen Bil. Ens., İstanbul.

Tabur, M., Izciler, M., Gul, F., Karacan, I., 2009. Abrasive wear behavior of boronized AISI 8620 steel. Wear, 266, 1106-1112.

Ulu, S., Kayalı, Y., Güneş, İ., 2013. Surface Borided SAE 1020 Steel With Dual Phase Core Microstructure. Materials Science And Technology, 29-3, 255-260.

Uslu, I., Comert, H., Ipek, M., Ozdemir, O., Bindal, C., 2007. Evaluation of borides formed on AISI P20 steel. Materials and Design, 28, 55-61.

Uysal, M., 2006. CrN, TiN Kaplanmış ve Kaplanmamış AISI 304 paslanmaz çeliğin korozyon özellikleri. Yüksek Lisans Tezi, Gazi Üni., Fen Bil.Ens., Ankara. 